\title{
Traumatic endophthalmitis with intraocular metallic foreign body
}

\author{
Imane Chabbar $\odot$, Amina Berraho ${ }^{\odot}$ \\ Ophthalmology B Department, Ibn Sina University Hospital, Rabat, Morocco
}

\begin{abstract}
BACKGROUND: Post-traumatic endophthalmitis with retained intraocular foreign body is a severe complication of open globe injuries. It is generally associated with poor visual outcome and requires prompt and adapted management.

CASE REPORT: A 39-year-old male patient presented with open globe injury of the right eye due to a metallic foreign body projection. He was a victim of a neglected work accident 10 days ago when hammering a metallic bar. Visual acuity on admission was LP (+) in the right eye. The Slit-lamp examination revealed perikeratic injection, edematous cornea and severe inflammation of the anterior chamber with hypopyon. Ocular ultrasound showed a heterogeneous vitreous organization compatible with a vitreous abscess. Orbito-cerebral CT scan revealed a retained intraocular metallic foreign body located in the posterior segment, within the vitreous humor. The patient received local and general antibiotherapy associated with intravitreal injections of vancomycin and ceftazidime followed by a vitrectomy to remove the intraocular foreign body. The visual outcome was poor with an evolution towards phtysis bulbi. The aim of this case report is to study the risk factors of post-traumatic endophthalmitis with retained intraocular foreign body and to examine treatment principles and visual outcome of this severe complication.
\end{abstract}

KEY WORDS: traumatic endophthalmitis; intraocular foreign body; posterior segment; risk factor; intravitreal antibiotic, vitrectomy

Ophthalmol J 2020; Vol. 5, 125-129

\section{INTRODUCTION}

Post-traumatic endophthalmitis is a rare but serious complication of penetrating eye injuries. Despite therapeutic advances, it represents a major turning point for the patient's visual outcome [1].

The incidence of post-traumatic endophthalmitis varies between 3 and $17 \%$ of open globe injuries $[2,3]$. The presence of intraocular foreign body is a major risk factor increasing this incidence to $48 \%$ $[4,5]$. This increase in incidence is mainly related to the nature of the intraocular foreign body, the ocular damage and the contamination that it causes [6].

The management of this severe situation is not fully codified and several aspects remain controver- sial, including the timing of removal of the intraocular foreign body, systemic or intravitreal antibiotherapy, the timing and the route of administration of corticosteroid therapy The prevention of such a complication therefore remains an important issue in the management of patients with open globe injuries. Prompt management with suturing of the wound is the only clearly established recommendation.

The aim of this case report is to study the risk factors of post-traumatic endophthalmitis with retained intraocular foreign body and to examine treatment principles and visual outcome of this severe complication. 


\section{CASE REPORT}

We report a case of a 39-year-old male patient, working as an industrial blacksmith, without any pathological history, presented with open globe trauma of the right eye caused by a metallic foreign body projection. Indeed, he was a victim of a neglected work accident 10 days ago, when hammering a metal bar. On admission, the visual acuity was LP + in OD and 10/10 in OS. The right eye examination (Fig. 1) revealed eyelids swelling, conjunctival and perikeratic congestion, edematous cornea without fluorescein staining and severe inflammation of the anterior chamber with hypopyon. The examination doesn't found any obvious wounds. The intraocular pressure was about $16 \mathrm{~mm} \mathrm{Hg}$. The examination of the lens and the eye fundus was difficult, hampered by corneal edema and anterior chamber inflammation.

Ocular ultrasound (Fig. 2) showed an intact lens in natural disposition, a heterogeneous vitreous organization in favor of a vitreous abscess with membrane formation, a choroidal thickening and an intact retina. An urgent orbito-cerebral CT scan (Fig. 3) revealed a millimeter foreign body located in the posterior segment, within the vitreous humor, of metallic nature, respecting the eyeball sphericity.

An urgent hospitalization was indicated and vitreous samples for cultures were sent for microbiological analysis. The patient was treated by systemic broadspectrum antibiotherapy based on intravenous

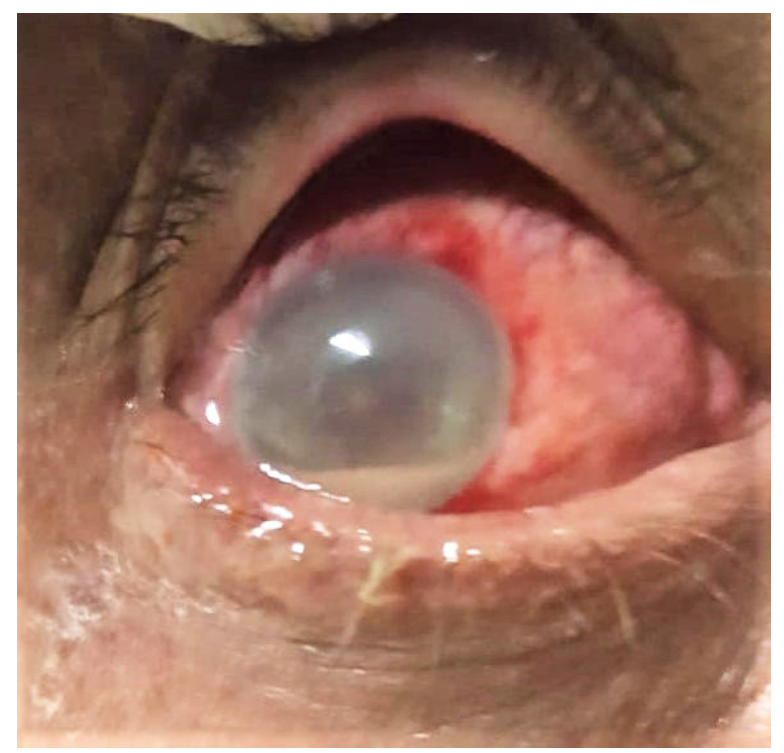

FIGURE 1. Severe inflammation of the anterior segment of the right eye: conjunctival and perikeratic congestion, corneal edema, aqueous flare and hypopyon

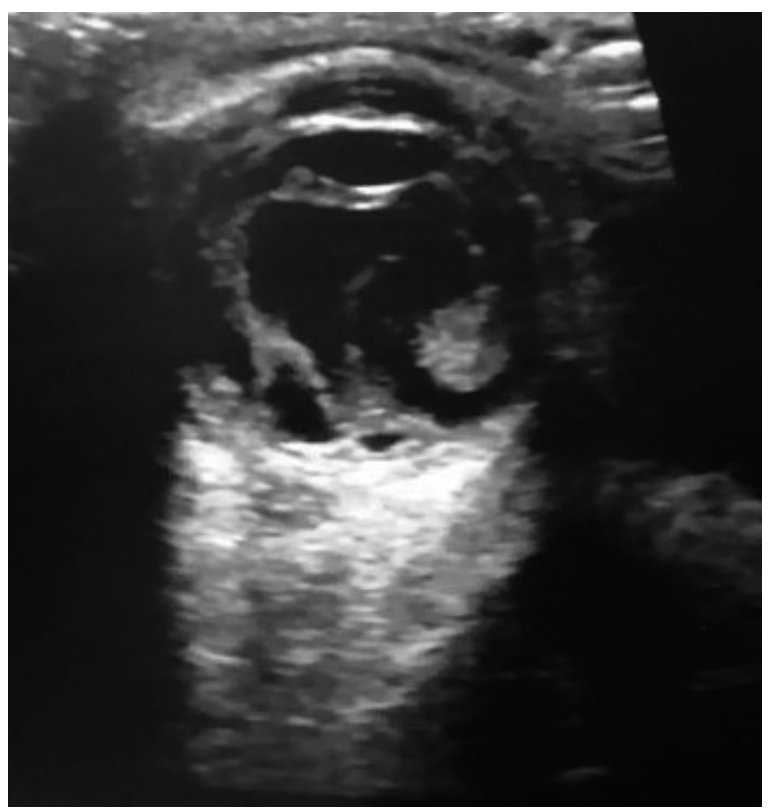

FIGURE 2. Ocular ultrasound of the right eye, showing a vitreous abscess with membrane formation, a choroidal thickening and an intact retina

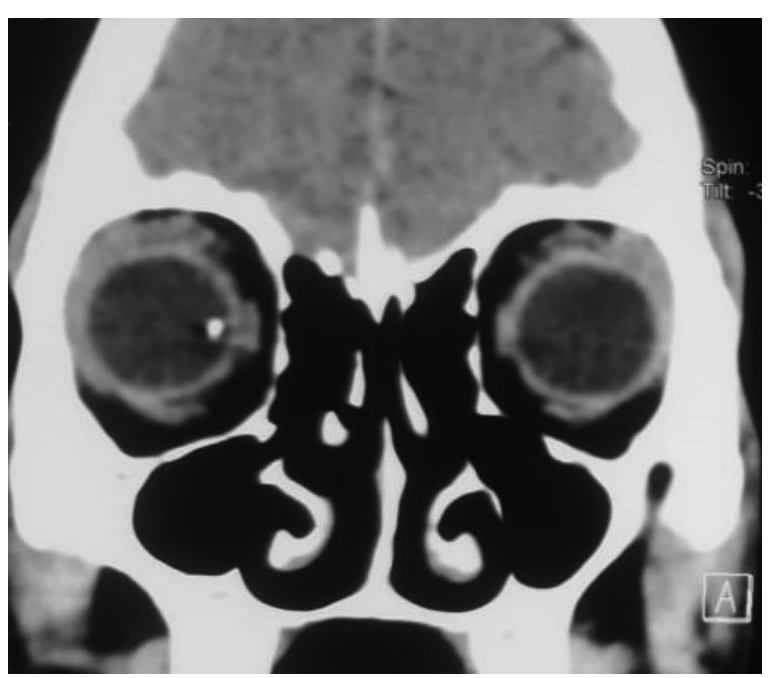

FIGURE 3. Orbito-cerebral CT scan showing in the right eye: posterior segment intraocular foreign of metallic nature, respecting the eyeball sphericity

injection of Ceftriaxone $2 \mathrm{~g} / 24$ hours and Fluoroquinolone per os $750 \mathrm{mg} / 12$ hours, then adapted to the microbiological results that revealed Staphylococcus Epidermidis. Local treatment with fortified antibiotic eye drops was also associated. Moreover, the patient received 2 intravitreal injections of vancomycin $1 \mathrm{mg} / 0.1 \mathrm{~mL}$ and ceftazidime $2 \mathrm{mg} / 0.1 \mathrm{~mL}$ 48 hours apart followed by a vitrectomy in order to reduce the infectious mass, to improve antibiotics 
diffusion and to remove the foreign body after enlargement of the sclerotomy. Indeed, given the poor visibility due to the corneal edema, the vitrectomy was limited and central with conservative vitreous shaving to avoid possible retinal tears on a retina weakened by the infection and the trauma. Silicone oil tamponade was not performed. The evolution was unfavorable and visual outcome was poor with the evolution towards phthisis bulbi.

\section{DISCUSSION}

Post-traumatic endophthalmitis is a rare but severe complication of penetrating eye injuries. The presence of an intraocular foreign body (IOFB) is a major risk factor increasing the incidence of this complication. A prospective randomized study, evaluating the interest of preventive treatment of open globe trauma, observes a significant association between post-traumatic endophthalmitis and the presence of retained IOFBs $[7,8]$.

The initially marked inflammation and deep eye pain may hamper the initial clinical examination and thus delay diagnosis and treatment, further worsening the visual prognosis. Yang and al. demonstrated in a retrospective study over a 20 -year-period that $87 \%$ of open globe injuries patients with IOFB presented clinical signs of endophthalmitis at initial examination [9]. An increased risk of endophthalmitis was significantly related to delay in treatment exceeding $24 \mathrm{~h}$ after injury. Indeed, in our case, the long consultation delay, around 10 days, resulted in a poor visual outcome.

A retained IOFB represents a risk factor promoting microbial proliferation. The nature of IOFB is a determining parameter [6]. Indeed, organic IOFBs are very septic and significantly increase the risk of endophthalmitis [10]. However, IOFB retained during war trauma are associated with a low risk of infection. They are able to self-sterilize due to the nature of high velocity or high-temperature projectiles that are involved.

The anatomic location of the IOFB is another factor influencing significantly the visual outcome. IOFBs retained in the posterior segment of the eye compromise the visual prognosis and cause severe eye damage more than those retained in the anterior segment $[11,12]$. Woodcock and al. demonstrated a significant relationship between poor visual acuity less than 20/200 and posterior location of IOFB [13].

The timing of surgical management of IOFB is still discussed. In the literature, several studies recommended the urgent removal of IOFB in order to reduce the risk of endophthalmitis and prevent proliferative vitreoretinopathy (PVR) and tractional complications [14]. In addition, Jonas et al. noted a satisfactory rate of anatomical success associated with early removal [15]. They found a lower PVR rate when IOFB was removed early within the first 24 hours after the trauma. Colyer et al. also showed a high risk of PVR when removal of IOFB was delayed, however, they found that functional success mainly depended on the extent and severity of intraocular damage and not on the vitrectomy delay [16].

In contrast, Ferrari and coworkers reported, in a retrospective study of 273 patients, that endophthalmitis was noted only in $2.3 \%$ of cases when the IOFB removal was before 24 hours after injury versus $15.7 \%$ when it was delayed beyond 24 hours [17].

Several authors have studied the influence of lens capsule rupture on the risk of post-traumatic endophthalmitis $[18,19]$. These studies have demonstrated an increased risk of endophthalmitis associated with traumatic lens rupture. Indeed, the opening of the lens capsule facilitates the intravitreal penetration of microorganisms. In addition, this rupture hampers the normal circulation of aqueous humor, thus decreasing the elimination of microorganisms that proliferate and feed on the ruptured lens $[17,20]$.

The involvement of the posterior segment of the eye, particularly the retina, considerably influences the visual outcome. The association of retinal tears or even retinal detachment with endophthalmitis is an aggravating factor associated with a very poor visual prognosis and progression to the eyeball phtysis [21]. Older age could be also a risk factor due to the decrease in the immune response with age [22].

According to the literature, open globe injuries with the externalization of the intraocular tissues massively expose the globe to microorganisms' penetration and are associated with a high risk of endophthalmitis [23]. This exposure is greater if the wounds are very posterior and difficult to repair, thus promoting microbial invasion of posterior segment of the eye. However, Zhang et al. [24] noted, through a large retrospective study, that the risk of post-traumatic endophthalmitis is not increased by the presence of posterior wounds and that, on the contrary, the presence of uveal prolapse through the wound was a protective factor that may plug the wound and protect the eye against the development 
of endophthalmitis. Further studies are needed to determine the real implication of uveal prolapse in the occurrence of post-traumatic endophthalmitis.

Thanks to the identification of these risk factors, the ophthalmologist can select the open globe injuries with IOFB having a high risk of endophthalmitis and then adapt their management according to this risk. Systemic antibioprophylaxis, after open globe injuries, is recommended to prevent traumatic endophthalmitis by the majority of authors, based on broad-spectrum antibiotics with good eye penetration [25].

Medical treatment of post-traumatic endophthalmitis is based on intravitreal injections of antibiotics. This route of administration is more efficient since it allows antibiotics to penetrate directly inside the globe and to reach very high concentrations [26]. Antibiotics must act against Gram-positive (particularly Staphylococcus epidermidis) and Gram-negative bacteria. For initial therapy, the combination of intravitreal injection of vancomycin and ceftazidime is recommended $[25,27,28]$. While awaiting culture results, intravenous antibiotic therapy is usually associated, covering both Gram-positive and Gram-negative organisms with several available options [29]. In order to increase the concentration of antibiotics in the eye, topical antibiotics or better fortified topical antibiotics are often combined with intravitreal injections of antibiotics, but they penetrate weakly inside the vitreous [30]. Subconjunctival injections achieve therapeutic levels of antibiotics in the anterior segment [31]. They are especially indicated in patients where multi-daily instillation of drops cannot be performed.

All administration modalities of corticosteroids in the management of traumatic endophthalmitis are still under discussion: the timing, the route of administration and the effective dose.

Theoretically, Corticosteroids provide a powerful anti-inflammatory action to quickly control the infection, shorten the endophthalmitis evolution and thus improve the visual outcome in anatomical and functional terms [32].

In addition to medical treatment, some authors recommend early vitrectomy [33] in patients with post-traumatic endophthalmitis. The basic principle of vitrectomy in the management of endophthalmitis is comparable to the principle of surgical drainage of collected abscesses. Moreover, the infected vitreous becomes very condensed with the formation of vitreous membranes increasing the risk of retinal traction. The techniques of vitrectomy are diverse; some authors recommend a large vitrectomy with posterior cortex removal [34]. However, given the poor visibility in the posterior segment, other authors recommend more limited initial vitrectomy without posterior hyaloid removal because that can be complicated by retinal tears or even retinal detachment. Some studies noted that the use of silicone oil tamponade after vitrectomy is recommended in the presence of retinal detachment or if there is a high risk of occult retinal tears [35-37]. In addition, thanks to its antimicrobial properties, the presence of silicone oil may protect against the vitreous cavity reinfection.

Our patient was a real challenge. The management of traumatic endophthalmitis was particularly difficult with the poor visual outcome, due to the following reasons: the neglected open globe injury with delayed consultation beyond 10 days, the poor initial visual acuity $(\mathrm{LP}+)$, the presence of posterior segment IOFB and the conservative surgical management because of the important corneal edema and the severe eye inflammation.

\section{CONCLUSION}

Despite medical and surgical advances, the visual prognosis of post-traumatic endophthalmitis with retained IOFB remains very poor. However, appropriate management based on rapid wound repair, IOFB extraction, early vitrectomy, and intravitreal injections of antibiotics may treat traumatic endophthalmitis and improve the visual outcome in some patients.

\section{REFERENCES}

1. Williams DF, Mieler WF, Abrams GW, et al. Results and prognostic factors in penetrating ocular injuries with retained intraocular foreign bodies. Ophthalmology. 1988; 95(7): 911-916, doi: 10.1016/s01616420(88)33069-1, indexed in Pubmed: 3262852.

2. Azad R, Ravi K, Talwar D, et al. Pars plana vitrectomy with or without silicone oil endotamponade in post-traumatic endophthalmitis. Graefes Arch Clin Exp Ophthalmol. 2003; 241(6): 478-483, doi: 10.1007/ s00417-003-0670-4, indexed in Pubmed: 12756578.

3. Kong GYX, Henderson RH, Sandhu SS, et al. Wound-related complications and clinical outcomes following open globe injury repair. Clin Exp Ophthalmol. 2015; 43(6): 508-513, doi: 10.1111/ceo.12511, indexed in Pubmed: 25688653.

4. Kuhn F, Morris R, Witherspoon CD, et al. The Birmingham Eye Trauma Terminology system (BETT). J Fr Ophtalmol. 2004; 27(2): 206-210, doi: 10.1016/s0181-5512(04)96122-0.

5. Boldt H, Pulido J, Blodi C, et al. Rural Endophthalmitis. Ophthalmology. 1989; 96(12): 1722-1726, doi: 10.1016/s0161-6420(89)32658-3.

6. ESSEX R, YI Q, CHARLES P, et al. Post-traumatic endophthalmitis. Ophthalmology. 2004; 111(11): 2015-2022, doi: 10.1016/j. ophtha.2003.09.041.

7. Soheilian M, Rafati N, Mohebbi MR, et al. Prophylaxis of acute posttraumatic bacterial endophthalmitis: a multicenter, randomized clinical 
trial of intraocular antibiotic injection, report 2. Arch Ophthalmol. 2007; 125(4): 460-465, doi: 10.1001/archopht.125.4.460, indexed in Pubmed: 17420365.

8. Dehghani AR, Rezaei L, Salam H, et al. Post traumatic endophthalmitis: incidence and risk factors. Glob J Health Sci. 2014; 6(6): 68-72, doi: 10.5539/gjhs.v6n6p68, indexed in Pubmed: 25363107.

9. Yang CS, Lu CK, Lee FL, et al. Treatment and outcome of traumatic endophthalmitis in open globe injury with retained intraocular foreign body. Ophthalmologica. 2010; 224(2): 79-85, doi: 10.1159/000235725, indexed in Pubmed: 19707031.

10. Jonas JB, Knorr HL, Budde WM. Prognostic factors in ocular injuries caused by intraocular or retrobulbar foreign bodies. Ophthalmology. 2000; 107(5): 823-828, doi: 10.1016/s0161-6420(00)00079-8, indexed in Pubmed: 10811069.

11. Woodcock MGL, Scott RAH, Huntbach J, et al. Mass and shape as factors in intraocular foreign body injuries. Ophthalmology. 2006; 113(12): 2262-2269, doi: 10.1016/j.ophtha.2006.06.002, indexed in Pubmed: 17157134.

12. Cebulla CM, Flynn HW. Endophthalmitis after open globe injuries. Am J Ophthalmol. 2009; 147(4): 567-568, doi: 10.1016/j.ajo.2008.12.016, indexed in Pubmed: 19327442.

13. Woodcock MGL, Scott RAH, Huntbach J, et al. Mass and shape as factors in intraocular foreign body injuries. Ophthalmology. 2006; 113(12): 2262-2269, doi: 10.1016/j.ophtha.2006.06.002, indexed in Pubmed: 17157134.

14. Chaudhry IA, Shamsi FA, Al-Harthi E, et al. Incidence and visual outcome of endophthalmitis associated with intraocular foreign bodies. Graefes Arch Clin Exp Ophthalmol. 2008; 246(2): 181-186, doi: 10.1007/s00417-007-0586-5, indexed in Pubmed: 17468878 .

15. Jonas JB, Budde WM. Early versus late removal of retained intraocular foreign bodies. Retina. 1999; 19(3): 193-197, doi: 10.1097/00006982199905000-00003, indexed in Pubmed: 10380023.

16. Colyer MH, Weber ED, Weichel ED, et al. and al. Delayed intraocular foreign body removal without endophthalmitis during Operations Iraqi Freedom and Enduring Freedom. Ophthalmology. 2007; 114(8): 1439-1447, doi: 10.1016/j.ophtha.2006.10.052, indexed in Pubmed: 17331579 .

17. Ferrari TM, Cardascia N, Di Gesù I, et al. Early versus late removal of retained intraocular foreign bodies. Retina. 2001; 21(1): 92-93, doi: 10.1097/00006982-200102000-00026, indexed in Pubmed: 11217947.

18. Narang S, Gupta V, Simalandhi P, et al. Paediatric open globe injuries. Visual outcome and risk factors for endophthalmitis. Indian J Ophthalmol. 2004; 52(1): 29-34, indexed in Pubmed: 15132376.

19. Sabaci G, Bayer A, Mutlu FM, et al. Endophthalmitis after deadlyweapon-related open-globe injuries: risk factors, value of prophylactic antibiotics, and visual outcomes. Am J Ophthalmol. 2002; 133(1): 62-69, doi: 10.1016/s0002-9394(01)01320-4, indexed in Pubmed: 11755840.

20. Bhagat N, Nagori S, Zarbin M. Post-traumatic Infectious Endophthalmitis. Surv Ophthalmol. 2011; 56(3): 214-251, doi: 10.1016/j. survophthal.2010.09.002, indexed in Pubmed: 21397289.

21. Gokce G, Sobaci G, Ozgonul C. Post-Traumatic Endophthalmitis: A Mini-Review. Semin Ophthalmol. 2015; 30(5-6): 470-474, doi: 10.31 09/08820538.2013.877939, indexed in Pubmed: 24571685.
22. Thompson WS, Rubsamen PE, Flynn HW, et al. Endophthalmitis after penetrating trauma. Risk factors and visual acuity outcomes. Ophthalmology. 1995; 102(11): 1696-1701, doi: 10.1016/s01616420(95)30807-x, indexed in Pubmed: 9098264.

23. Duch-Samper AM, Menezo JL, Hurtado-Sarrió M. Endophthalmitis following penetrating eye injuries. Acta Ophthalmol Scand. 1997; 75(1): 104-106, doi: 10.1111/j.1600-0420.1997.tb00263.x, indexed in Pubmed: 9088415.

24. Zhang $\mathrm{Y}$, Zhang MN, Jiang $\mathrm{CH}$, et al. Endophthalmitis following open globe injury. Br J Ophthalmol. 2010; 94(1): 111-114, doi: 10.1136/ bjo.2009.164913, indexed in Pubmed: 19692359.

25. El Chehab H, Renard JP, Dot C. [Post-traumatic endophthalmitis]. J Fr Ophtalmol. 2016; 39(1): 98-106, doi: 10.1016/j.jfo.2015.08.005, indexed in Pubmed: 26563842.

26. Baum J, Peyman GA, Barza M. Intravitreal administration of antibiotic in the treatment of bacterial endophthalmitis. III. Consensus. Surv Ophthalmol. 1982; 26(4): 204-206, doi: 10.1016/0039-6257(82)90080-7, indexed in Pubmed: 6978542.

27. Chhabra S, Kunimoto DY, Kazi L, et al. Endophthalmitis after open globe injury: microbiologic spectrum and susceptibilities of isolates. Am J Ophthalmol. 2006; 142(5): 852-854, doi: 10.1016/j.ajo.2006.05.024, indexed in Pubmed: 17056367.

28. Narang S, Gupta V, Gupta A, et al. Role of prophylactic intravitreal antibiotics in open globe injuries. Indian J Ophthalmol. 2003; 51(1): 39-44, indexed in Pubmed: 12701861.

29. Kresloff MS, Castellarin AA, Zarbin MA. Endophthalmitis. Surv Ophthalmol. 1998; 43(3): 193-224, doi: 10.1016/s0039-6257(98)00036-8, indexed in Pubmed: 9862309.

30. Peyman GA, May DR, Homer PI, et al. Penetration of gentamicin into the aphakic eye. Ann Ophthalmol. 1977; 9(7): 871-880, indexed in Pubmed: 302661

31. Theodore FH. Bacterial Endophthalmitis after Cataract Surgery. Int Ophthalmol Clin. 1964; 4: 839-859, doi: 10.1097/00004397-19641200000005, indexed in Pubmed: 14231940.

32. Park SS, Samiy N, Ruoff K, et al. Effect of intravitreal dexamethasone in treatment of pneumococcal endophthalmitis in rabbits. Arch Ophthalmol. 1995; 113(10): 1324-1329, doi: 10.1001/ archopht.1995.01100100112040, indexed in Pubmed: 7575268.

33. Mittra RA, Mieler WF. Controversies in the management of open-globe injuries involving the posterior segment. Surv Ophthalmol. 1999; 44(3): 215-225, doi: 10.1016/s0039-6257(99)00104-6, indexed in Pubmed: 10588440.

34. Abu el-Asrar AM, Tabbara KF. Clostridium perfringens endophthalmitis. Doc Ophthalmol. 1994; 87(2): 177-182, doi: 10.1007/BF01204795, indexed in Pubmed: 7835187.

35. Azad R, Ravi K, Talwar D, et al. Pars plana vitrectomy with or without silicone oil endotamponade in post-traumatic endophthalmitis. Graefes Arch Clin Exp Ophthalmol. 2003; 241(6): 478-483, doi: 10.1007/ s00417-003-0670-4, indexed in Pubmed: 12756578.

36. Bali $\mathrm{E}$, Huyghe Ph, Caspers $\mathrm{L}$, et al. Vitrectomy and silicone oil in the treatment of acute endophthalmitis. Preliminary results. Bull Soc Belge Ophtalmol. 2003(288): 9-14, indexed in Pubmed: 12879720.

37. Siqueira RC, Gil AD, Canamary $F$, et al. Pars plana vitrectomy and silicone oil tamponade for acute endophthalmitis treatment. Arq Bras Oftalmol. 2009; 72(1): 28-32, doi: 10.1590/s000427492009000100006 , indexed in Pubmed: 19347118. 